\title{
Trazos de lo político a partir de Fenomenología de la percepción
}

\author{
(4) Leonardo Eiff \\ Consejo Nacional de Investigaciones Científicas y Técnicas; Universidad Nacional de \\ General Sarmiento, Argentina
}

Recibido el o9/og/2020. Aceptado el 28/11/2020.

\begin{abstract}
Resumen
El artículo procura destacar la relevancia teórico-política de una obra filosófica como Fenomenología de la percepción en el planteo de algunas cuestiones centrales para el pensamiento político. La estrategia fue la siguiente: en primer lugar, identificar las zonas de la obra donde irrumpen cuestiones políticas; en segundo lugar, extraer las consecuencias a partir de una hipótesis de lectura que postula, por un lado, el vínculo entre libertad-poder-espacio y, por el otro, entre institución-autoridad-tiempo. Finalmente, se trata de poner en relación ambos vínculos a través de la figura del cuerpo y de su posible deriva hacia la noción de cuerpo político.
\end{abstract}

Palabras clave: autoridad, cuerpo, poder.

\section{Strokes of the political from Phenomenology of perception}

\begin{abstract}
The paper tries to highlight the theoretical-political relevance of a philosophical work as Phenomenology of perception in the posing of some central questions for political thought. The strategy was the following: first, to identify the areas of the work where political issues arise; second, to extract the consequences from a reading hypothesis that postulates, on the one hand, the link between freedom-power-space and, on the other, institution-authority-time. Finally, it is a matter of relating both links through the figure of the body and its possible drift towards the notion of body politic.
\end{abstract}

Keywords: Authority, Body, Power. 


\section{Introducción}

¿Dónde rastrear lo político en Fenomenología de la percepción? En primer lugar, debemos partir de lo evidente: no hay ningún abordaje político específico. No tendría por qué haberlo, ciertamente. En segundo lugar, es imperioso huir de las facilidades conceptuales que escanden relevancias políticas aquí y allá. Sin embargo, con las precauciones necesarias, Fenomenología de la percepción irradia politicidad si logramos atisbarla desde un ángulo peculiar. El artículo procurará identificar algunos de esos trazos. La pregunta, entonces, no es solo dónde rastrear sino también cómo trazar el sendero de lo político. Cuestión fundamental, puesto que nuestro objetivo requiere desviarse de una relación demasiado evidente: la de fenomenología y marxismo en la obra de Merleau-Ponty (cf. Eiff, 2014). Es la que menta el filósofo de manera explícita, como una suerte de deriva de sus hallazgos fenomenológicos - que conduce, por otra parte, a distinguir los textos filosóficos de los escritos políticos-, alrededor de las figuras de conciencia, praxis, experiencia, historia. Sin soslayar esa dimensión -la irrupción de la conciencia perceptiva en la Historia - sobre la que ya hemos abundantemente trabajado en otros textos (cf. Eiff, 2014), aventuramos otro escenario, cuya propuesta consiste en extraer lo político de los motivos medulares de la obra filosófica merleau-pontyana. Para ello, como condición previa, debemos clarificar nuestro enfoque y luego explicitar el plexo de nuestra lectura.

De modo contemporáneo a la redacción merleau-pontyana de Fenomenología de la percepción, Alexandre Kojève escribe, con simulada sorpresa, que la noción de autoridad ha sido poco estudiada, y que, sin embargo: "es totalmente imposible indagar el poder político y la estructura del Estado sin saber qué es la autoridad" (Kojève, 2004: 49). Merleau-Pony, como Marx, quien según el propio Kojève soslayó completamente el problema de la autoridad, ${ }^{1}$ parece desconocer una de las problemáticas nodales del pensar político: la articulación y la diferenciación entre auctoritas y potestas. $^{2}$ La relación entre ambos conceptos es crucial para escudriñar adecuadamente la especificidad de lo político. En este sentido, nuestro enfoque pretende ser fiel a la relación problemática entre autoridad y poder. De hecho, consideramos que calibrar la lectura de la obra política de Merleau-Ponty a partir de las figuras de conciencia, cuerpo, praxis, acción, etc., desoyendo la mentada articulación, conduce a un callejón sin salida, puesto que liga la reflexión a los ciclos de la revolución y la democracia vinculando, de modo estrecho y dependiente, la filosofía merleau-pontyana con la obra de Claude Lefort $(1978,1981,1986)$.

Ahora bien, despejada la perspectiva general se impone la pregunta: ¿cómo procederemos? Se trata de tentar, sin forzamiento alguno de la textualidad, un vínculo entre dos dimensiones conceptuales que no parecen ir de la mano en la obra de nuestro autor, pero que resultan sin embargo fundamentales para un pensamiento profundo de lo político: una que liga libertad y espacio a través de la cuestión del poder; y aquella otra que une institución (e historia) y tiempo bajo la égida de la autoridad. Cada dimensión encierra un nodo de sentido, y nuestra pregunta guía será si es posible y

1 Curiosamente los diversos marxismos, que, al menos desde la década de los setenta, discuten con brío acerca de la existencia de una teoría del Estado en Marx, ignoran la conexión entre la dificultad marxiana para teorizar el Estado y la completa ausencia de una reflexión sobre la noción de autoridad.

2 Recordamos la célebre frase de Cicerón: "residiendo el poder en el pueblo y la autoridad en el senado" (Cum potestas in populo, auctoritas in senatu sit) (Cicerón, De Legibus, 3, 28). 
cómo anudar uno y otro. Desde nuestro punto de vista, las dos dimensiones permiten reabrir la interrogación de lo político en Fenomenología de la percepción en la medida en que - y esta es la tesis que nos gustaría mostrar aquí- se encuentran en la noción de corporalidad tal como la entiende Merleau-Ponty. El propósito, en este sentido, es vislumbrar destellos de lo político, que no necesariamente son los que el autor quisiera destacar (cf. Merleau-Ponty, 1955). Nuestra lectura comparte el gesto, aunque evidentemente inscripto en otro registro, de Roberto Esposito con Sein und Zeit: "la heideggeriana no es una filosofía política, sino precisamente su desconstrucción en el pensamiento de la comunidad" (Esposito, 2003: 156). ${ }^{3}$ La lectura del parágrafo 26 orienta la decisiva proposición: el mundo del Dasein es mundo común. La analítica del Mitsein deconstruye la filosofía política. En nuestro caso, examinaremos las zonas de la Fenomenología de la percepción que, desde la más completa extrañeza respecto a los carriles centrales de la filosofía política, ventilan aspectos de lo político.

Para desarrollar nuestra cuestión, el recorrido versará alrededor de tópicos conocidos: libertad, espacio, temporalidad y cuerpo. El esquema será el siguiente: comenzaremos con la noción merleau-pontyana de libertad, continuaremos con la identificación de un tipo de espacialidad que acoge una intelección política de la libertad; el vértice que une ambas figuras, libertad y espacio, será el poder. Luego, indagaremos la noción de institución en relación con la temporalidad histórica; su vértice será, en este caso, la figura de autoridad. En el último apartado, consagrado al cuerpo, al cuerpo político en rigor, buscaremos, a través de esta noción, desarrollar una convergencia posible entre las dos tríadas anteriores.

\section{Libertad y espacio}

Hannah Arendt escribió que a la pregunta por el sentido de la política debe responderse: "el sentido de la política es la libertad" (Arendt, 2005: 62). La contundente simplicidad de la respuesta escondía su aspecto vidrioso, puesto que las relaciones entre política y libertad, y política y sentido habían perdido su evidencia. Los problemas y la ilación entre sentido, política y libertad pueden propiciar un acercamiento entre Merleau-Ponty y la gran reconstrucción arendtiana del tejido de la acción pública ante un mundo gobernado por la oikonomí (Tassin, 2012) Sin embargo, MerleauPonty pertenece a la tradición dialéctica, y a menudo lo atraviesa la tentación de reducir la política a la dominación; de allí que su acercamiento a la figura de libertad acaso caiga dentro de la malla lanzada por Isaiah Berlin en su texto homónimo: dos conceptos de libertad. ¿O no está ligado el derrotero merleau-pontyano a una severa crítica de la ilusoria libertad liberal y a una concomitante ponderación de la libertad como reconocimiento y emancipación? Las potencialidades y las inquietudes de una concepción positiva de la libertad atañen a la reflexión política merleau-pontyana. De hecho, una lectura superficial de las primeras páginas del último capítulo de Fenomenología de la percepción barrunta una confrontación entre una visión negativa de la libertad (hobbesiano-liberal, digamos, y en este caso, como se sabe, no es para nada un oxímoron) y una visión positiva surgida del deseo de ser sujeto (autorrealizarse). En un caso se trata de "estar libre de algo", en el otro consiste en "ser libre para algo" (Berlin, 2001: 60). Ahora bien, es sabido que la configuración arendtiana de la libertad al anudar la constitutiva pluralidad de la condición humana con la acción como creación de poder común (mediante el estar juntos), horada la contraposición entre los dos conceptos de libertad (cf. Arendt, 1995). "Estamos mezclados con el mundo 
y con los demás en una confusión inextricable", "no hay libertad sin algo de poder" (Merleau-Ponty, 1945: 519). Dos citas merleau-pontyanas, entre muchas otras que es factible extraer casi al azar, nos reenvían al punto de partida y nos obligan a escrutar la relevancia filosófica de la libertad en la Fenomenología de la percepción.

\section{Comenzamos con dos cuestiones en algún sentido preliminares:}

En primer lugar, cabe destacar que el capítulo sobre la libertad es sorprendente, porque a pesar de cerrar el libro, no significa una conclusión de este, sino la apertura hacia nuevas problemáticas que la Fenomenología de la percepción no había abordado cabalmente. La reflexión sobre "La liberté" parece más fuera que dentro de la Fenomenologia de la percepción si seguimos estrictamente su derrotero argumental. En rigor, Fenomenología de la percepción concluye con el capítulo sobre "La temporalité", donde se indaga el tiempo para cerrar los temas trabajados dando una síntesis que ilumine cabalmente la superación del diferendo entre el realismo y el intelectualismo, resuelva los restos de la problemática trascendental y esboce una nueva idea de sujeto corporal. La demostración del sentido de la imbricación entre temporalidad y subjetividad permite llegar a la conclusión clave de la obra: el cuerpo es motricidad, espacialidad y temporalidad. Merleau-Ponty ultima las principales hipótesis de la obra en este capítulo, el paso indagatorio por el tiempo tiene un afán resolutivo que se corrobora en las últimas cinco páginas. ¿Por qué, entonces, agregar un capítulo sobre la libertad? ¿Y por qué al final?, ¿acaso es el esbozo de una filosofía práctica soslayada en los dos libros inaugurales dedicados a la función reveladora y significativa del cuerpo?

En segundo lugar, es el capítulo que expone la divergencia con la flamante filosofía de Sartre, puesto que su objetivo es derruir la médula de la ontología fenomenológica sartreana. En El sery la nada, Sartre busca confrontar todas las hipótesis causalistas y deterministas sobre la libertad humana. La libertad no es un efecto ni depende de motivos o voluntades, no supone tampoco el éxito de la acción libre desplegada. La libertad carece de motivos. El ser-humano elige perpetuamente su ser porque no tiene fundamento, la conciencia vomitada en el mundo es una nada de ser que se elige a cada instante confundiéndose con determinados proyectos, siempre fugada de sí-misma; la conciencia en su situación de perpetua huida no puede dejar de elegirse. La libertad es este permanente deslizamiento sobre el mundo por el que la conciencia se escurre del yo-objeto. Para Sartre, el sentido adviene al mundo por la libertad. Es el hacer humano lo que carga de sentido al mundo. Así, un obstáculo, un límite, un aquí, un allá, un estado de ánimo, adquieren sentido, o distintos sentidos, según la libre elección de la conciencia.

Merleau-Ponty se va a recostar en el planteo sartreano para impugnar los presupuestos deterministas y objetivistas de la libertad alentados por la tradición positivista, para luego, en un movimiento reflexivo característico, desarmar la argumentación sartreana con el siguiente razonamiento: si todo está en nuestro poder, si el peso y las imposibilidades del mundo son siempre escollos puestos por mi libertad -es decir, de mi conciencia sobre mi conciencia - no hay manera de saber qué es la libertad. Qué la distingue, cuándo y cómo emerge. Con la noción sartreana de libertad no hay acción libre, sostiene Merleau-Ponty. No hay acción libre, porque la postura sartreana obtura toda posibilidad de opción y de comienzo. La libertad en Sartre está más acá de la acción porque no tenemos que realizarla, está en todas partes, colorea la totalidad de nuestro ser. En este sentido, se le amputa a la libertad humana toda experiencia vivida, ya que no importa mi itinerario, ni mi posición social, puesto que siempre cuento con la capacidad negadora de la conciencia libre. No hay antes y después, ni flujos temporales, la libertad está más allá del tiempo y del espacio. La opción desaparece porque la elección entre esto y aquello no pone en tela de juicio 
la libertad humana. En rigor: si la libertad no se arriesga en la opción, no es viable hablar de elección y en consecuencia la noción sartreana de elegirse pierde sentido, ya que si siempre elijo jamás podré circunscribir y distinguir situaciones de libertad y situaciones de opresión, y por lo tanto las relaciones humanas, lo político y lo social, se tornan ininteligibles.

Hay sin dudas mayores matices, incluso una elocuente ponderación de Merleau-Ponty en marcado contraste con los fenomenólogos merleau-pontyanos quienes compiten en el desdén hacia Sartre; pero, con todo, Merleau-Ponty indica sin ambages que los caminos sartreanos de la libertad no llevan a ninguna parte. Con una salvedad: la noción sartreana de situación. La libertad, para Sartre, discurre situada. Más allá del previsible anclaje corporal, Merleau-Ponty traduce: "No hay libertad sin campo" (1945: 502). Pensar la libertad implica abordar la espacialidad (allí reside la diferencia radical, puesto que nadificar la libertad supone anular el espacio). Por otra parte, la fórmula patética estamos condenados a la libertad no solo merece ser contrastada con el correctivo de rigor: estamos condenados al sentido, sino que la libertad espacialmente situada exige una reformulación del problema del poder.

La libertad, escrutada políticamente, tiene que ver con el poder antes que con el querer. Por tanto, es crucial distinguir libertad y voluntad - "la libertad filosófica, la libertad de la voluntad, es importante solo para quienes viven fuera de las comunidades políticas como individuos solitarios (Arendt, 2002: 432)-, y considerar libertad y poder como sinónimos. La politicidad de la libertad reenvía al nosotros plural antes que a los juegos con nosotros mismos (es claro que Sartre, aunque se esfuerce por distinguir libertad y voluntad procurando saldar el escollo del solipsismo postulando la mirada del otro como constitución originaria del para-sí, es filosóficamente incapaz de articular un nosotros, un ser-con, y, además, en la Crítica de la razón dialéctica el nosotros práctico, pergeñado como grupo, acarrea una insoslayable precariedad ontológica). Consideramos que Merleau-Ponty desgaja la libertad de la voluntad (es decir: la voluntad libre según la tradición) al inferirla según su capacidad práctica y no como facultad espiritual. Por ejemplo: tenemos siempre el poder de interrumpir, pero esto supone podercomenzar (Merleau-Ponty, 1945: 501). La potencia del comienzo reconcilia a la libertad con la acción, le otorga carnadura y la aleja de cualquier valoración ex nihilo. Sintéticamente: la libertad es poder estar juntos de una manera no determinada por la naturaleza del oikos. En consecuencia, la libertad no puede ser disposición interior (como en el ejemplo estoico del esclavo libre, retomado por Sartre), puesto que necesita manifestarse en el mundo, y para ello requiere de un espacio de aparición. En términos más estrictos: la capacidad práctica que potencia un nosotros, depende de un tipo específico de espacialidad. Si leemos el capítulo con atención podremos observar que detrás de la clásica contraposición entre las visiones científicas, causales o deterministas, que niegan la libertad a manos de la necesidad, y las visiones idealistas que postulan una libertad inscripta en un sujeto acósmico, anida no solo el rastreo de una fenomenología de la intersubjetividad - y en este punto fenomenología y marxismo no tendrían mayores diferencias- o la dotación de una subjetividad acorde con la filosofía de la historia marxiana, sino un esbozo de indagación de la politicidad inherente a la figura de la libertad. Amparados en este derrotero argumental cabe vislumbrar la proximidad con el enfoque arendtiano.

Ahora bien, Arendt indica que, al menos para la modernidad, un correcto abordaje de la libertad exige salir de la estricta reflexión filosófica, puesto que ésta la subsume en una jerarquía que postula un orden necesario o la confunde con la voluntad o el libre albedrío. La autora atisba otra constelación ajena a la tradición filosófica: aquella que proviene de las estelas de las revoluciones y su sentido práctico. De esta forma, Arendt enfatiza la fractura entre ontología y praxis. La metafísica, que, desde Aristóteles, reconoce la fisura y, al mismo tiempo, procura enmendarla con suerte dispar; se enerva, 
de manera excepcional, en el campo de la política. Merleau-Ponty, consciente o no, rehusa aceptar la imposibilidad de la sutura y persigue, a partir del despeje de una fenomenología de la percepción, una ontología que contenga una región específica gobernada por la praxis. Sabemos que dicho programa filosófico sufrió no pocas variantes (cf. Barbaras 1991, 1998; Larison, 2016), pero, con todo, las exploraciones práctico-políticas merleau-pontyanas nunca dejaron de proyectarse ontológicamente. Puede constatarse observando cómo la dimensión de la conciencia acecha los primeros escritos políticos. Sin embargo, el proyecto esgrime un mero esbozo, es apenas un umbral. En este sentido, las preguntas que hicimos anteriormente sobre las razones de escritura de un capítulo que desborda la obra pueden responderse bajo el signo del prolegómeno: prolegómenos para una ontología política futura. Los subsiguientes ensayos políticos -v.gr: Humanismo y terror o Las aventuras de la dialéctica-caben en la misma signatura. La libertad marca el tránsito de la fenomenología a la ontología y abre un conjunto nuevo de perspectivas.

El enraizamiento de la libertad implica una reflexión sobre la espacialidad. De las diversas formas de espacialidad que trajina Fenomenología de la percepción, destacamos una vinculación posible entre el espacio vivido y el mundo social. La frase antes citada: "no hay libertad sin campo", puede interpretarse bajo la lógica sensible del campo perceptivo, pero, a nuestro juicio de manera más sugestiva, puede asirse como imbricación entre el espacio de los afectos y el espacio de la acción. ¿Cabe pensar a partir de Merleau-Ponty una relación entre la afectividad de los cuerpos y la esfera pública? ¿Su común espacialidad, sin la cual no hay percepción ni libertad, alcanza para pespuntear un terreno compartido? Nuestras respuestas no se conforman con el tradicional camino fenomenológico que indica un continuum expansivo desde un polo originario de vivencias (que parte, por ejemplo, del tacto hasta alcanzar el cuerpo político). Desde nuestro punto de vista, debemos evitar convertir la lectura merleaupontyana en una máquina de reproducción ampliada de la experiencia. Partimos de un lugar opuesto: la discontinuidad de la acción respecto a cualquier naturalismo perceptivo o, en otros términos, afirmamos la autopoiesis de lo público. Perseguir la imbricación implica la renuncia a los orígenes.

Si antes señalamos la proximidad entre Arendt y Merleau-Ponty, ahora vale vislumbrar sus diferendos, ligados, desde nuestro particular visor político, en torno a las fronteras del espacio de aparición. Tanto Arendt como los teóricos de la acción comunicativa y la democracia deliberativa (sin desconocer sus diferencias, que nos aventuramos a suspender en aras de la progresión del argumento), asientan la crucial esfera pública en la primacía del discurso. Sea vindicando la retórica sofística frente al platonismo o sea informados por el descubrimiento moderno de la fuerza ilocucionaria del lenguaje, las teorías políticas reivindicativas de la luminosidad de lo público pagan el precio de la desincorporación de los sujetos. Y lo pagan convencidos puesto que consideran cualquier remisión a la corporalidad (o a las pasiones o afectos) como una peligrosa rémora teológico-política, desde la voluntad general rousseauniana hasta el Poder-Uno totalitario. Así, por ejemplo, Habermas postula una tesis de la soberanía popular, completamente emancipada de un sujeto-pueblo sustancial, resuelta en procedimientos comunicativos de intersubjetividad (cf. Habermas, 2005: 605-20). Merleau-Ponty no ha dejado de polemizar con cualquier absolutización del lenguaje, sospechando que su vínculo privilegiado con el sentido de la acción disolvía la política en diversos planos de normatividad o subordinaba su legitimidad a la tutela jurídica de la acción. Arendt, evidentemente, no comulga con los intentos de reemplazar la contingencia de lo político por procedimientos jurídicos validados por una conversación entre iguales; no obstante, la carencia de una reflexión aguda sobre el cuerpo, concebido desde prejuicios "anti-vitalistas" (Arendt, 2006: 100) que, en rigor, se deben a una zona de perdurable influjo heideggeriano, la sitúa en una línea divergente respecto a nuestro planteo. 
Hay una modalidad existencial de nuestra experiencia del espacio, cuyo ser perceptivo anula los objetos claros y distintos, forjando una espacialidad sin cosas. Espacio antropológico, llama Merleau-Ponty a las modificaciones que sufre la espacialidad de acuerdo con la singularización de nuestro estar en el mundo. Ofrece tres ejemplos: el sueño, el mito y la esquizofrenia. Tales vivencias proyectan una espacialidad, donde alto-bajo, derecha-izquierda, lejos-cerca, adolecen de una exacta correspondencia geométrica, puesto que constituyen espacios de existencia. Por ejemplo, en la novela iniciática de Goethe podemos distinguir cómo el paisaje, antes que la geografía, es un existenciario cuya contemplación depende de las vibraciones del sentir amoroso del joven Werther. Los patrones de experiencia brindados por Merleau-Ponty pretenden recrear las relaciones entre lo aparente y lo real más allá de la cerrazón racionalista, a pesar del reconocimiento de la imposibilidad de recostar la existencia plenamente en los espacios antropológicos (entendidos a partir de sus derivas ilusorias o alucinantes). Asimismo, Merleau-Ponty sugiere que "la descripción del espacio antropológico podría ser continuada indefinidamente" (Merleau-Ponty, 1945: 340), y nos reenvía a una nota que certifica esa oportunidad a partir de la percepción estética del cuadro pictórico o el movimiento de los cuerpos danzantes ${ }^{4}$. Pues bien, Merleau-Ponty no lo hace, pero es plausible considerar que existe de manera latente un pasaje hacia la espacialidad de lo político. La esfera pública configurada como espacio de aparición carece de cosas (la relación del anthropos con las cosas privatiza el mundo, sea como uso o como propiedad), es un ejemplo de espacio antropológico. De todas formas, vale destacar el rasgo afectivo-corporal del espacio existencial mentado por MerleauPonty contra las nociones de espacio público regidas meramente por la acción y el discurso. La identidad entre el ser y el aparecer cincelada desde el cuerpo propio implica la irrupción de un umbral de indistinción entre lo social y lo político. Un espacio purgado de su orientación "natural" hacia las cosas, recorta sus fronteras imbricando lo social y lo político.

El mundo social es una dimensión de existencia. Es decir: no es mero objeto para una conciencia ni puede ser reducido a hecho por la ciencia. En este sentido, cabe destacar la ajustada descripción del espacio social como espacio antropológico, cuya figura nodal es: coexistencia. La narración sthendaliana de la experiencia de Fabrizio en la batalla de Waterloo no solo revela la contrariedad de una perspectiva desenraizada, sino que también ilumina la peculiaridad del lugar, cuya espacialidad acoge los posibles. La modalidad existencial de lo social instituye el espacio donde el poder es sinónimo de libertad.

Evidentemente Merleau-Ponty compone las dimensiones del espacio vivido y el mundo social prolongando, y explorando los puntos de quiebre respecto al primer período de la fenomenología, las descripciones husserlianas del mundo vivido (Lebenswelt) o los parágrafos 56-58 de las Meditaciones cartesianas sobre las comunidades intersubjetivas; no obstante, llamamos la atención en torno a los recurrentes ejemplos políticos que ofrece nuestro autor. Tanto hacia el final del capítulo "Autrui et le monde humain" como en un momento estratégico del derrotero del capítulo sobre "La liberté", irrumpen las situaciones revolucionarias en la Rusia del 17. MerleauPonty, como sugerimos antes, retoma la noción sartreana de situación, restituyendo un pendant entre los rasgos tácitos y la decisión sin parangón. Que la situación de clase sea vivida (Merleau-Ponty, 1945: 420) admite un ramillete de elementos cuya explicación solo puede provenir del enraizamiento espacio-existencial del poder-libertad. Acontecimiento y experiencia de la coexistencia. Allí se juegan las relaciones entre 
lo real y lo posible - que Bergson recreó en un ensayo célebre-; no es la realidad una actualización de posibles, es lo real aquello que abre la posibilidad de lo posible. Llamo real, en sentido político, a la constelación: espacio-poder-libertad. Y daré un ejemplo extraído del acervo de escenas descriptas por John Reed en Diez días que conmovieron al mundo, que creo, sin alarde alguno, escenifica mejor dicha constelación que las ilustraciones que brinda Fenomenología de la percepción:

La puerta de la gran escuela de equitación Miguel estaba abierta de par en par. Dos centinelas quisieron detenernos, pero franqueamos precipitadamente la entrada, sordos a sus requerimientos. El interior estaba débilmente iluminado por una lámpara de arco colgada bajo el techo de la inmensa sala, cuyas altas columnas e hileras de ventanas se difuminaban en la penumbra (...) alrededor unos dos mil soldados vestidos con uniformes oscuros que parecían perdidos en la inmensidad de este edificio imperial (...) Se sucedieron los oradores, hablando tan pronto en medio de un silencio tenso como rodeados de clamores de aprobación o de cólera: ¿actuaremos o mantendremos una actitud neutral? (...) Janjunov trató de hacer uso de la palabra, pero como por todas partes se gritaba: ¡A votar, a votar!, cedió y leyó una resolución proponiendo que se retirara al representante de los broneviks en el Comité Militar Revolucionario y se declarara la neutralidad de éstos en la guerra civil. Los que estuvieran a favor de la moción debían pasar a la derecha; los que estuvieran en contra, a la izquierda. Hubo un momento de vacilación, de espera muda; luego se inició un movimiento hacia la izquierda, que se fue haciendo más rápido gradualmente; cientos de soldados vigorosos, tropezando los unos con los otros, avanzaron en masa compacta sobre el piso sucio, en la penumbra... Hay que imaginarse que una lucha semejante se desarrolló en todos los cuarteles de la ciudad, en todos los distritos, en todo el frente, en toda Rusia. Hay que imaginarse en los regimientos a los Krylenkos aporreados de cansancio, corriendo de un lugar a otro, discutiendo, amenazando, suplicando. Hay que imaginarse, finalmente, las mismas escenas en todos los locales de los sindicatos, en las fábricas, en los pueblos, en todos los navíos dispersos de la flota; hay que imaginarse a cientos de miles de rusos por todo el país, las miradas fijas en los oradores, obreros y campesinos, marinos, trabajando intensamente por comprender y decidir, pensando con sus fuerzas $y$ tomando, finalmente, de manera tan unánime, su decisión. Así fue la revolución rusa (Reed, 1980: 150-53).

Hay que imaginarse el gesto corporal, el movimiento afectivo, su disponerse a; bajo el brío fogoso de los discursos, el caudal de palabras, entre las penumbras de la historia... el espacio del tiempo.

\section{Historia e Institución y tiempo}

La extensa nota que cierra el capítulo "Le corps comme être sexué» cifra el planteamiento merleau-pontyano del problema de la historia (sus flecos se extenderán en la serie de textos histórico-políticos de la posguerra). Batalla contra la reducción de la existencia humana a un elemento determinante: la sexualidad o la economía. Punto de partida del largo y ríspido diálogo con el psicoanálisis y el marxismo. No se trata de acotar la totalidad de la existencia a la economía, sino de reintegrar la esfera económica en la universalidad concreta de la historia. Merleau-Ponty arguye que el materialismo histórico ofrece menos una explicación causal mediante la economía que una comprensión, mediante el destaque de la producción y los modos de trabajar, del "modo de existir y coexistir" (Merleau-Ponty, 1945: 210). Interpretación existencial del marxismo, que se anima con una teoría existencial de la historia, cuya ambigüedad no puede ser reprochada, porque ella es la estofa misma de la historicidad. Sartre 
tentará una teoría similar en su ensayo Materialismo y revolución (Merleau-Ponty, 1949), y notemos que Merleau-Ponty convoca el caso de Paul Valéry para sugerir que, si bien su obra admite una dilucidación económico-social, su poesía no puede reducirse a un episodio de enajenación mercantil (Merleau-Ponty, 1945: 212). Sartre, 15 años después, usó el mismo caso y lo transformó en dictum: "Valery es un intelectual pequeño burgués, no hay ninguna duda. Pero cualquier intelectual pequeño burgués no es Valery. La insuficiencia heurística del marxismo cabe en esas dos frases" (Sartre, 1960: 44). Así, la concepción existencial de la historia esbozada por Merleau-Ponty, puesto que conserva la pluralidad en el seno de la totalidad, procuraba corregir las insuficiencias heurísticas de los marxismos dominantes para que el sentido cabal de la filosofía marxiana aflorara, al menos como una promesa de realización en la práctica. En la nota al pie Merleau-Ponty insiste con ejemplos de situaciones revolucionarias (casi idénticos a los otros que ya señalamos) que manifiestan la ambigüedad originaria como carne de la historia.

Ahora bien, el centro vacío del esbozo de concepción existencial de la historia puede vislumbrarse en la palabra mitsein, que apenas asoma para ilustrar una correspondencia recíproca con las relaciones económicas. Es un reenvío a Heidegger que obliga a preguntar: ¿por qué Merleau-Ponty no introdujo jamás a lo largo de la obra los parágrafos (72-77) de Sein und Zeit consagrados a la relación entre temporalidad e historicidad? El gestarse histórico del Dasein cuyo hilo conductor es una hermenéutica existenciaria de la temporalidad: la historia es inherente al ser del Dasein. La constitución fundamental de la historicidad -incluidas, por supuesto, sus derivas inquietantes ligadas al "destino colectivo", el gestarse histórico del Volk- era el único camino para arribar a Marx de manera renovada. Una inflexión, o acceso a Marx despojándose de los marxismos realmente existentes, que es destello de politicidad en el seno de Fenomenología de la percepción; no obstante, la ausencia de Heidegger en las consideraciones merleau-pontyanas sobre la historia obturó el camino o lo hizo tropezar a menudo con una subjetividad histórica de raigambre hegeliana. "La praxis en Heidegger y en Marx" es el título de una conferencia pronunciada por Carlos Astrada a su vuelta de Alemania en el significativo año de 1933 -luego fue insertada, con algunas modificaciones, como capítulo en su último libro: Martín Heidegger (de la analítica ontológica a la dimensión dialéctica), publicado en 1970-. En el breve escrito Astrada explora la comparación entre "un filósofo de inspiración ontológica y el economista teórico y revolucionario práctico de tan hondo influjo en el área histórica de las discusiones y luchas del presente" (Astrada, 2005: 107). Heidegger y Marx comparten el punto de partida, el anclaje, el inicio del filosofar: la esfera pragmática y cotidiana de la existencia. Así, contra el postulado de un sujeto acósmico meditante o de un mundo que solo se da para una conciencia, ambas perspectivas incoan desde el factum de la existencia. Constelación que declina cuatro rasgos: 1) la historicidad de la existencia; 2) el mitsein y el hombre como conjunto de relaciones sociales; 3) relación práctico-transformadora con el mundo, amanualidad y cuidado (sorge), trabajo y revolución; 4) existencia situada y contexto histórico-social. Las Tesis sobre Feuerbach son leídas por Astrada como el esbozo de una filosofía de la praxis - veta que, entre otros, sabrá explotar Gramsci en sus conocidos Cuadernos de la cárcel- para atizar una hermeneusis comparativa con Heidegger, quien realiza la analítica existencial del Dasein a través del discurrir de la cotidianeidad. La praxis existencial es teórica y práctica, ya que supone una comprensión específica, un entramado singular, cuya posibilidad ontológica está dada por la facticidad del Dasein y su peculiar modo de ser. Como dijimos, la praxis existencial, posición inicial de Heidegger, remite a Marx, quien reconocía que toda vida social es práctica: "la praxis reconocida como el factor decisivo, como la actitud transformadora de la existencia se revierte en teoría de la transformación de la estructura social" (Astrada, ibid.: 55). Ahora bien, la praxis existencial posee un rasgo propio: la historicidad. El estar-en-el-mundo del Dasein es un gestarse histórico con otros, y en Marx el enraizamiento social del viviente humano 
supone una resolución histórica. Concluye Astrada que, en este sentido, es patente la dimensión existencial de la posición marxista, cuya dialéctica, a diferencia del idealismo hegeliano, devino "el proceso vivo de un movimiento social de proyecciones planetarias" (Astrada, ibid.: 57). Desde el núcleo de Sein und Zeit, Astrada abrió una brecha que finalmente lo llevaría hasta, como dice Guillermo David (2004), el dragón de la dialéctica.

El itinerario ejemplar de Astrada, que, con matices, fue el de Marcuse o Sartre (combinar/fusionar: existencia y dialéctica), pudo ser el de Merleau-Ponty, pero no lo fue. Una explicación proviene del perdurable impacto de la filosofía husserliana: jes posible describir la mundanidad de la experiencia más allá de cómo el mundo aparece para una conciencia?, ¿es posible atisbar lo común desde la perspectiva de la intersubjetividad?, ¿la coexistencia supera la alternativa entre el ego y el alter ego?, ¿es posible franquear el ego meditante hacia un nosotros práctico? Las soluciones husserlianas no convencen, evidentemente, a Merleau-Ponty; pero no hay dudas que sus reflexiones siguen atemperadas por las preguntas del fundador de la fenomenología. Es lo que impide dilucidar el alcance de la ruptura heideggeriana vinculada al Mitsein y a la historicidad del Dasein, pero no impide atisbar que en la dialéctica anidan algunas respuestas para las inquietudes husserlianas. Ahora bien: ¿qué corresponde extraer de semejante magma filosófico? Al comienzo, nuestro autor tiende a convalidar una interpretación existencial de Hegel cuyo correlato es un enriquecimiento filosófico de la experiencia subjetiva. ${ }^{5}$ De ese modo, la dialéctica rescata al sujeto de la prisión del cogito y lo precipita en el terreno de la historia. Sin embargo, Merleau-Ponty no demora en avizorar que, como le espetó Lévi-Strauss a Sartre, se limitó a cambiar de prisión (Lévi-Strauss, 1964: 361). Es decir, el salto a la historia desde la conciencia solamente amplía la esfera de las cogitaciones al precio de una perenne intelección teleológica de la historicidad.

Advertimos nuestro desborde respecto a una estricta reconstrucción de los trazos políticos en Fenomenología de la percepción, pero permítasenos el desliz para sopesar un punto de insurgencia: no es posible recrear las relaciones entre subjetividad, intersubjetividad, comunidad, historicidad, sin una interrogación radical de la temporalidad. Es el meollo irresuelto de Fenomenología de la percepción, que revela, por la negativa, lo siguiente: sin recalibrar la figura de la temporalidad no es admisible pensar la política porfuera de la perspectiva de la conciencia.

A título de esbozo ofrecemos algunas pistas, tomando en consideración desarrollos posteriores de la filosofía merleau-pontyana, cuyo eje es la relación entre temporalidad y política, sin desconocer que el tiempo, como cifra de la filosofía, impone reflexiones que escapan a nuestro artículo. Aún así, conjeturamos que: en primer lugar, el derrotero hacia la Historia debe dimanar menos de una aglutinación fenomenológica de la experiencia subjetiva que de la apertura hacia la Sittlichkeit. En segundo lugar, la filosofía hegeliana del espíritu objetivo es la que admite un cotejo con las meditaciones husserlianas sobre las comunidades intersubjetivas de rango superior. Dos preguntas se desprenden de la comparación: ¿es posible la vida en común sin remitir a un polo privilegiado e irradiante de vivencias? ¿Cómo perdura el espacio público? Desde nuestro punto de vista, la respuesta no es la dialéctica del sujeto, sino la institución. A ella remite la interrogación política alrededor del tiempo: ¿cómo amparar la duración de lo común, el lugar de irrupción del poder/libertad? 
La tradición del pensamiento político conserva el tesoro de la respuesta: la duración de lo común se sostiene en la autoridad. La pregnancia de la filosofía de la historia nos habituó a considerar políticamente el tiempo desde la perspectiva del poder, es decir, desde la díada conservación / revolución (recordemos que Marx no abordó jamás el problema específico de la autoridad), pero una mirada más atenta connota que la politicidad del tiempo reenvía a la autoridad y no al poder. "El tiempo es la matriz de la autoridad" (Revault d'Allons, 2006: 13). Y no solo por su estribación: la tradición o la transmisión, sino por una figura expuesta de modo fulgurante por Merleau-Ponty: la durée publique (Merleau-Ponty, 1960: 28). Myriam Revault d'Allons, quien reflexiona en la estela de Paul Ricœur, anuda sagazmente autoridad, institución y durée publique. En efecto, la autoridad no es mera inercia de lo instituido, es la fuerza pregnante que mantiene, conserva y protege, el mundo común; por tanto, su temporalidad cursa tanto el pasado como el futuro, es meollo del tiempo. De algún modo, la imbricación merleau-pontyana entre lo político y lo social, su devenir común, implica la existencia de la institución como reservorio de autoridad. La tradición como olvido de los orígenes, las relaciones entre el origen cronológico y lo originario, la Urstifung, son nodos de inteligibilidad merleau-pontyanos a indagar en provecho de la figura del tiempo como matriz de la autoridad. En el mismo sentido, las tramas culturales e históricas que Merleau-Ponty rastrea bajo el nombre de institución (cf. Merleau-Ponty, 2003) pueden entreverarse con la Sittlichkeit hegeliana, que, una vez contrarrestada su clausura ontológica, puede recalibrarse como prosa del mundo. La eticidad es lien. Temporalidad común, que, al no ser extraña al sujeto ni pulverizar el sentimiento de sí, forja una argamasa institucional que permite a la acción desplegar su fulgor. En síntesis, y a futuro, una posible fenomenología de la institución puede releer de modo auspicioso el momento objetivo de la filosofía hegeliana del espíritu.

Recordemos el crucial ensayo arendtiano ¿Quées la autoridad? (1972)-probablemente la mayor reflexión y exégesis sobre el concepto que se publicó en el pasado siglorevela el carácter inextricable de la trinidad: religión, autoridad, tradición. La experiencia política de la fundación de la urbs romana tiene allí su origen legítimo. "El vigor de esa trinidad reside en la fuerza vinculante de un comienzo bajo el prisma de la autoridad al que los hombres están ligados por lazos religiosos a través de la tradición" (Arendt, 1972: 164). El extravío de la imbricación, o el intento de conservar algunos de sus polos prescindiendo de otros, explica el debilitamiento del sentido de lo político, puesto que su experiencia medular, la fundación, queda ensombrecida. Por otra parte, el ensayo arendtiano parece sugerir que para que suceda el origen de la política es imprescindible un elemento supra-humano. De manera similar los ejemplos maquiavelianos extraídos de la tradición mosaica o el legislador rousseauniano sugieren la misma perplejidad. La solución es pensar a los dioses como seres políticos. Con todo, Benveniste indica que la semántica del concepto de autoridad remite a su origen divino, un atributo de los dioses. La figura porta "cualidades misteriosas", "valores oscuros y poderosos"; don reservado a los pocos hombres que hacen surgir algo nuevo en el mundo (Benveniste, 1983: 327). Sea admitiendo la verosimilitud de lo divino o postulando una interpretación antrópica, la pregunta por la existencia en un mundo sin autoridad fue crucial en el pasado siglo - desde Nietzsche, mejor dicho-, cuyo entronque con la pregunta por el sentido de la política tras la huida de los dioses es palmario. ¿Qué sucede con la fragilidad inherente de los asuntos humanos sí carecemos de la institución que los romanos consideraban como la única forma de inmortalidad de la que son capaces los seres mortales? En Merleau-Ponty es una 
interrogación ausente, por eso puede sonar forzado su inclusión en las perspectivas teóricas que distinguen auctoritas y potestas.

La cuestión por formular es, entonces, la siguiente: ¿es plausible redescubrir el tesoro perdido de la noción de autoridad en el marco de las sociedades democráticas? Revault d'Allons juzga su posibilidad extrayendo uno de los flecos semánticos de la figura, aquella vinculada al "hacer existir"; el poder comenzar, que puede inscribirse sin contradicción alguna, en la continuidad de la durée publique. Comenzar-continuar, instituyente e instituido. Así, la pregunta por la perdurabilidad del vivir común en un mundo sin autoridad admite la apuesta por la reconciliación entre la democracia -comprendida lefortianamente: la indeterminación del lugar del poder-y el emblema de la autoridad. Pues bien, la reconciliación supone la omisión del lugar de lo religioso, puesto que es evidente la inherencia del poder político y el religioso en la experiencia romana de la fundación. Lo que parece iluminar la exégesis de la autoridad es la imposibilidad política de la democracia moderna (y es uno de los focos de la irresoluble conflictividad entre el pensar arendtiano y la democracia liberal).

En suma, si no estamos dispuesto a suprimir estas cuestiones, es indudable que debemos vislumbrar, sin remilgos, los senderos nodales del pensamiento merleaupontyano en el contexto de la perplejidad moderna respecto a la autoridad; $y$, sin embargo, y al mismo tiempo, consideramos viable añadir a la exégesis política de la auctoritas a la propuesta de imbricación entre institución y temporalidad a partir de una renovada exploración de la crucial cuestión merleau-pontyana: el cuerpo.

\section{Cuerpos}

Como anunciáramos al comienzo de este trabajo, nuestra tarea será ahora centrar los vectores y lazos abiertos por las dimensiones conceptuales de la libertad-espacio y poder, y la institución-tiempo y autoridad, en un campo semántico común: el cuerpo.

No se trata de hacer del cuerpo un ente totalizante capaz de atraer hacia sí un conjunto vasto de problemáticas; el camino será otro, ligado a la tentativa anterior, es decir, la urdimbre de una política que sitúe en el centro de su preocupación el descubrimiento de espacios comunes contorneados por la afectividad, no solo por el discurso, y enraizados en una dinámica temporal regida por la institución dilucidada a partir de su eminente vínculo con la tradición autoritativa.

La metáfora del cuerpo político es de capital importancia en la historia del pensamiento político. Las analogías anatómicas entre el Rey como cabeza y el pueblo como miembros, cuya unidad forja el reino, provienen del medioevo y penetran, con matices, en el organismo moderno. También sus reversos: las purgas, sangrías y enfermedades a curar o eliminar para restañar el orden corporal. Lo medular, sin embargo, es la estricta concomitancia entre el cuerpo político y una temporalidad propia. La Fenomenología de la percepción, que obviamente ubica en el corazón de la reflexión filosófica la figura del cuerpo, concibiendo la corporalidad en un horizonte propio de espacialidad y temporalidad, entreabre la pregunta por la politicidad de ese cuerpo. Pregunta que no procuramos responder en el sentido de los modos de subjetivación que producen los cuerpos disidentes, sino rastreando una pista concreta alojada en Fenomenología de la percepción: la especificidad temporal del cuerpo. Desarrollos ulteriores de la filosofía merleau-pontyana suscitarán una cesura con ciertos aspectos del análisis fenomenológico de la temporalidad, pero el ligamen crucial entre temporalidad y experiencia corporal perdurará. La persecución de la huella es la única vía de acceso merleau-pontyana a uno de los arcanos nodales de la política: la relación (espaciotemporal) entre auctoritas y potestas. 
Recordemos que este problema se gesta a lo largo del Medioevo, cuando la Iglesia necesitaba legitimar un gobierno temporal y los proto-estados seculares, regidos por príncipes mundanos, anhelaban lo sobrenatural para legitimar su poder, imbricar lo incorporal y lo corporal. En el magnífico e inagotable Los dos cuerpos del rey, Kantorowicz (2012) sugiere que la clásica oposición entre lo espiritual y lo temporal esconde una sutil convergencia alrededor de dos nociones: 1) corpus mysticum, 2) aevum (El primero corresponde al surgimiento sociológico, orgánico, político-moral, de la corporación; el segundo evoca una esfera singular del tiempo entendido como continuidad (ni eternidad ni cambio). En conjunto, se trata de la irrupción de una institución novedosa: corpus politicum (Kantorowicz, 2012:317) Veamos con algún detalle las tesis de Kantorowicz, que ilustran el vínculo estrecho entre cuerpo y temporalidad.

En primer lugar, Kantorowicz desarrolla la figura del Corpus mysticum (2012: 210-21) destacando los cambios histórico-semántico de su uso; primero vinculado a la doble naturaleza del cuerpo de Cristo y luego al cuerpo político de la iglesia como gobierno temporal. Según nuestro autor, la iglesia estaba habituada, desde sus albores, a pensar bajo la metáfora paulina del corpus Christi. Un cuerpo cuya cabeza es Cristo. Ese cuerpo constituía la totalidad de la sociedad cristiana, es decir, incluía a todos los creyentes (pasados, presentes y futuros). El corpus mysticum, por su parte, señala Kantorowicz, significaba la hostia consagrada. En ningún caso, la metáfora original del cuerpo habilitaba un uso político. Ahora bien, la iglesia, real y concreta, y su cabeza, real y concreta, el papa, estaba en liza con diversos príncipes seculares; en consecuencia, urgía hallar una forma mundana de gobierno conectada, por supuesto, con Cristo, cuyo vicario en la tierra, como sabemos, es el papa. La búsqueda, sugiere el historiador, marca el pasaje del dominio litúrgico al dominio jurídico, en los usos teológicos y canonistas del cuerpo (Kantorowicz, 2012: 217). La hostia consagrada será el cuerpo verdadero y natural de Cristo, y el cuerpo místico el aparato administrativo y técnico de gobierno eclesial: Corpus Christi juridicum (Kantorowicz, 2012: 221). Estamos ante una nueva distinción no idéntica a la de Cristo como persona con dos naturalezas, puesto que apunta al hallazgo de un método de gobierno. El cuerpo de Cristo adquiere politicidad como cuerpo colectivo. De modo coincidente, prosigue Kantorowicz, la filosofía medieval emprende una nueva lectura de Aristóteles (Averroes, Tomás, etc.) que recuperaba un modelo jerárquico, orgánico y corporativo para calibrar la sociedad. Tomás concibe a la Iglesia como cuerpo místico (corpus Ecclesiae mysticum), cuyo rasgo fenoménico es social y político (2012: 224-5). Tomás sustituye, habitualmente, el lenguaje litúrgico por el jurídico para asir el funcionamiento gubernativo de la Iglesia, en cuanto gobierno de la cristiandad. Así, se consuma un desplazamiento: el corpus Christi señala el cuerpo natural individual como corpus verum bajo el dogma de la transustanciación, y la Iglesia, como cuerpo místico, será un cuerpo político-colectivo, supraindividual. El uso político de la metáfora del cuerpo es, desde ahora, colectivo y corporativo. Por otra parte, los estados seculares arrastran el problema opuesto: ¿cómo dotar de un halo místico al poder temporal a fin de elevarlo más allá de su existencia física? Kantorowicz sostiene, en varias oportunidades, que el Estado surge a partir de un juego de espejos (mimesis, oposición y superación) con el lenguaje y las prácticas eclesiales; en este caso, respecto a la doctrina corporativa del cuerpo místico (Kantorowicz, ibid:: 209, 243). Según nuestro autor, las transferencias operan, centralmente, de dos maneras: 1) las metáforas organológicas servían para distinguir la cabeza (el príncipe) y los miembros (el pueblo), y el cuerpo individual / cuerpo colectivo, para teorizar la individualidad del príncipe y la ficción jurídica de lo colectivo o corporativo, intangible. 2) la recepción de Aristóteles instaba a pensar el estado secular como consecuencia de la razón natural y con fines morales intrínsecos. El cuerpo místico del estado era un cuerpo político y moral. En rigor, los juristas de las Coronas medievales incorporan la lengua teológica y canonista para ensanchar los márgenes de legitimidad del poder temporal gubernativo, pero, al mismo tiempo, la someten a una torsión (o, si se prefiere, secularización) cuyo objetivo es: convertir al 
gobierno en coeterno de la Iglesia (Kantorowicz, 2012: 221). Kantorowicz explora, entonces, la recuperación medieval del amor a la patria: pro patria mori. Elogio de la lealtad y glorificación de los muertos en batalla. Una conversión fue cumplida: la universalidad e inmortalidad del ungido pudo transformarse en la continuidad de un gobierno que nunca muere enraizado en una patria inmortal.

En segundo lugar, Kantorowicz indaga el surgimiento de una nueva dimensión temporal: Aevum (Kantorowicz 2012: 283-90). Durante la baja Edad media se suscitan, parafraseando a Koselleck, una serie de cambios en la semántica de los tiempos históricos. Por un lado, la reconsideración de la eternidad del mundo (infinito, sin principio ni fin), promovido desde el averroísmo radical, cuya flecha alcanza a Spinoza, hasta el aristotelismo oficial cultivado por Tomás; por el otro, la revalorización del tiempo contingente, las mutaciones legitimadas mediante la recuperación-reinterpretación de una vieja diosa romana: la fortuna, y la vindicación de la fama mundana, vinculada a una acción gloriosa arraigada en la memoria de los hombres. Se trata del concepto pagano de inmortalidad: permanecer en la memoria como consecuencia de acciones magistrales. En la Divina Comedia, algunos de los personajes condenados inquieren al poeta, preocupados por cómo son recordados o por cómo y quienes prosiguen sus luchas, como sucede en el Canto X con el inolvidable Farinata (Auerbach, 1950: 183). La recuperación y vindicación de la fortuna y la inmortalidad pagana marca, como bien señala Pocock, el comienzo del republicanismo "moderno", enfrentado a los dos colosos romanos, la iglesia y el imperio, que va a cristalizar en el humanismo cívico florentino (Pocock, 2008: 50). Ante el desafío, la filosofía escolástica reconfigura el dualismo agustiniano - la eternidad de Dios, un ahora siempre quieto, y el tiempo, vinculado al alma humana (Agustín interioriza la temporalidad, giro cuyo impacto filosófico sigue siendo incalculable), es decir, a la mutabilidad, la libertad y el pecado-, introduciendo una nueva temporalidad, cuyo halo "eterno" es la continuidad y su contingencia es consecuencia de su dependencia respecto a la productividad intelectual, ética y política humanas (Kantorowicz, 2012: 286-7).

El término utilizado por Kantorowicz, aevum (retomado del griego "Eón", un tiempo largo, cuasi eterno, en relación con la cronología diaria de Cronos y el tiempo-ahora del Kairós), es una categoría temporal infinita e interminable, puesta en liza con el concepto herético de "eternidad del mundo" de los averroístas, y, también, a los fines de descifrar un agudo problema teológico: el lugar de los ángeles. En efecto: el aevum es el espacio-tiempo de los ángeles. Inmortales, pero no eternos, temporales, pero no humanos. Lo destacable es la proximidad entre las ficciones jurídicas y las ficciones angélicas: "las personas ficticias desindividualizadas de los juristas se asemejaban necesariamente a los ángeles" (Kantorowicz, 2012: 289). Como antes, con el corpus mysticum, observamos, siguiendo a nuestro autor, una serie de préstamos entre el campo teológico y litúrgico y el campo jurídico-político; en este caso: una proliferación de metáforas "angelomórficas" junto a un empleo del vocabulario conceptual abstracto de la escolástica (universales, formas, géneros, especies), a fin de resolver dos cuestiones: la continuidad del cuerpo político y la perpetuidad del pueblo. Nace un nuevo concepto de continuidad institucional, cuasi infinita, que nunca muere, ligado, por supuesto, a la necesidad de legitimidad ciertas urgencias prácticas: el cobro de impuestos (2012: 291). Las tributaciones dejan de ser extraordinarias y privadas, vinculadas a las necesidades bélicas de los señores feudales, para ser regulares, públicas, vinculadas a la necesidad existencial del regnum. El incipiente aparato administrativo comienza una relación singular con el tiempo: registros, archivos, libros anuales, calendarios. Un uso del tiempo que fuerza la regularidad, continuidad y permanencia. Es el reino de la ficción jurídica, cuyo emblema es la impersonalización del cuerpo político a fin de sustraerlo de la insoslayable muerte natural: "la universitas no muere y es perpetua" (2012: 312). O, mejor dicho, se trata de un cambio de personalidad: la creación de una persona ficta (siglos después, Hobbes dirá que el Estado soberano es una persona 
artificial), cuya tarea es garantizar la continuidad mediante la jurisdicción, tributación, administración, del reino (2012: 310). Esta continuidad transcurre en el aevum.

Hasta aquí Kantorowicz. De nuestra parte, debemos reconocer que la inherencia entre lo religioso y lo político, que ya atisbamos en la experiencia romana de la fundación - y que ahora, vía la ruptura cristológica, adquiere una indudable fisonomía teológico-política- acaso nos obligue a confirma el célebre dictum schmittiano: "todos los conceptos centrales de la moderna teoría del Estado son conceptos teológicos secularizados" (Schmitt, 2009: 36). Sin embargo, no entraremos a esa discusión que atañe, siguiendo la frase de Blumberg, a la legitimidad de los tiempos modernos. De manera más acotada sugerimos que el rodeo por Kantorowicz explicita el entrelazo cuerpo-temporalidad en el seno de lo político, es decir, más allá de su específico enraizamiento dentro de la teología política medieval. Por ejemplo, el milagro de la permanencia que pesquisaron los teóricos políticos del período contractualista reenvía a ese entrelazo; lo mismo sucede con el espíritu objetivo y la política como Sittlichkeit, y no solo porque Hegel concibió la historia universal como una teodicea, sino porque el discurrir de las instituciones no puede depender ni de la inmediatez deseante de los sujetos ni de un continuo involucramiento divino en el mundo. Con todo, Corpus mysticum y Aevum son indicios para proceder a una reconstrucción del ligamen entre lo social y lo político a través de la afectividad corporal, que, sin negarlo, no se detiene en el indudable amarre entre lengua y política. La imbricación puede atisbarse en los juegos de préstamos entre cuerpo político y cuerpo colectivo inscriptos en una temporalidad común que no adviene a partir de la finitud del sujeto sino de la conjunción entre fundación $y$ continuidad (instituyente e instituido). Las figuras evocadas no deben confundirse con interpretaciones sociológicas del cuerpo colectivo en la senda de la solidaridad orgánica, estructural funcional o como prácticas y hábitos que hacen trabazón entre dominantes y dominados, puesto que lo crucial no es el cómo del cuerpo en el espacio social sino la dimensión temporal de la corporalidad; tampoco cabe la spinoziana composición de cuerpos según su utilidad común, porque la identificación entre necesidad y libertad y la singular ilación entre eternidad y temporalidad extravía nuestra pesquisa: el aevum del cuerpo político en la época de la crisis radical de lo moderno. ${ }^{8}$

En este sentido, el capítulo "La temporalité» de la Fenomenología de la percepción es a todas luces bifaz. Por un lado, condensa la vigencia de la perspectiva de la conciencia, pero por el otro, empuja, de manera soterrada, a través del cuerpo otra constelación temporal, y, en nuestro caso, suscita las siguientes preguntas: ¿cómo abrir el tiempo a la durée publique? ¿Cómo pensar el tiempo sin tropezar con su desinencia sucesiva o con una inevitable remisión a un polo privilegiado de vivencias? ¿Cómo desbordar hacia la política la gran salida heideggeriana del confinamiento subjetivo del tiempo a través de la reconciliación entre la mundanidad del Dasein y su originario temporalizarse? La magistral solución arendtiana: la vindicación del carácter dóxico y de sentido común que ofrece la conjuntiva aparición fenoménica del mundo y de la pluralidad humana, contra la asociación originaria entre publicidad e inautenticidad, cuyo mitsein cotidiano admite solo una salida individualizante y egotista puesto que el Dasein se proyecta decisoriamente hacia sus propias posibilidades mediante un recogimiento al ser en cada caso mío (Arendt, 2005: 202-4). Aun así, como ya sugerimos, Arendt soslaya el cuerpo. De hecho, a lo largo de su obra el cuerpo político es mera metáfora,

8 Las relaciones entre Spinoza y Merleau-Ponty merecen una exploración todavía, en gran medida, por realizar, aunque sin duda en la estela del trabajo filosófico realizado por Marilena Chaui. La poca atención merleau-pontyana, quién privilegió otras obras, no solo el inevitable Descartes sino también el más sorprendente Malebrache, y, por otra parte, la captura estructural materialista del filósofo de la Ética, sumado a lecturas demasiado dependientes de los ciclos de la filosofía francesa, dificultaron el vínculo. Con todo, la cuestión es cómo sospechar de aquello que Foucault descubrió en los publicistas de la razón de Estado como nuevo arte de gobierno en relación con Maquiavelo: el florentino es una pantalla para poder decir algo a través de él. Foucault explicita la cuestión con una de sus clásicas boutade arrojada contra los marxistas: "desde este punto de vista, nuestro Maquiavelo es Marx: aunque la cosa no pase por él, se dice a través de él" (Foucault, 2006: 285). Es lo que abunda en el spinozismo, y es lo que debe ser interrogado para liberar el camino de doble mano entre Spinoza y Merleau-Ponty. 
que casi no entraña consecuencias filosóficas. Por el contrario, el cuerpo "merleaupontyano" no es metafórico, es apertura al tiempo que conserva la dimensión sensible (logos del mundo estético), cuya doxa mundana es fe perceptiva. En otros términos, el cuerpo es eje vertebrador de una configuración espaciotemporal.

Para finalizar, de acuerdo con nuestra hipótesis, las dos dimensiones: libertad-espacio/ poder e institución-tiempo/autoridad, encuentran en la figura del cuerpo su filón común. La gramática del poder traza una geografía que admite la temporalidad de la acción - conjunción que evita transformar la retórica en ontología del discurso, esto es, pensamiento de sobrevuelo, desencarnado-, y la matriz temporal de la autoridad, en tanto pasado inscripto en un presente que se abre al futuro de manera no sucesiva, puede sintetizarse como espacio institucional transtemporal, cuya consecuencia es, al menos, un registro simultáneo de temporalidades. ${ }^{9}$ En suma, recuperar, merleaupontyanamente, la figura del cuerpo político, sin omitir su plexo teológico-político, aunque sin adscribir necesariamente al paradigma de la teología-política, permite explorar un entramado peculiar entre filosofía y política: la constelación espacial y temporal del poder y la autoridad enraizadas en el cuerpo como vida común. 


\section{Bibliografía}

"Agamben, G. (2008). El reino y la gloria: Una genealogía teológica de la economía y del gobierno. Buenos Aires: Adriana Hidalgo.

" Arendt, H. (1972). Qu'est-ce que l'autorité? La crise de la culture. París: Gallimard.

》 Arendt, H. (1995). La condición humana. Barcelona: Paidós.

"Arendt, H. (2002). La vida del espíritu. Buenos Aires: Paidós.

"Arendt, H. (2005). "Qué es la filosofía de la existencia" en Ensayos de comprensión 1930-1954. Madrid: Caparrós.

》Arendt, H. (2005). ¿Qué es la política? Buenos Aires: Paidós.

»Arendt, H. (2006). Sobre la violencia. Madrid: Alianza

» Astrada, C. (1952). La revolución existencialista. La Plata: Nueva destino.

》 Astrada, C. (2005). Martín Heidegger. Buenos Aires: Quadrata.

» Auerbach, E. (1950). Mimesis. La Representación de la realidad en la literatura occidental. México: FCE.

" Barbaras, R. (1991). De l'être du phénomène. Sur l'ontologie de Merleau-Ponty. Grenoble: J. Millón.

" Barbaras, R. (1998). Le tournant de l'expérience. Recherches sur la philosophie de Merleau-Ponty. París: Vrin

» Benveniste, E. (1983). Vocabulario de instituciones indoeuropeas. Madrid: Taurus.

"Berlin, Isaiah. (2001). Dos conceptos de libertad y otros escritos. Madrid: Alianza.

» Blumenberg, H. (2008). La legitimidad de la edad moderna. Valencia: Pre-textos.

»David, G (2004). Carlos Astrada: La filosofía argentina. Buenos Aires: El cielo por asalto.

»Didi-Huberman, G. (1997). Lo que vemos, lo que nos mira. Buenos Aires: Manantial.

》Eiff, L. (2014). Merleau-Ponty, filósofo de lo político. Los polvorines: Eds. Ungs.

"Esposito, R. (2003). Communitas: Origen y destino de la comunidad. Buenos Aires: Amarrortu.

» Foucault, M. (2006). Seguridad, territorio y población. Buenos Aires: FCE.

» Habermas, J. (2005). Facticidad y validez. Madrid: Trotta.

»Heidegger, M. (1944). El ser y el tiempo. México. FCE.

» Kantorowicz, E. (2012). Los dos cuerpos del rey: Un estudio de teología medieval. Madrid: Akal.

"Kojève, A. (2004). La notion de l'autorité. París: Gallimard.

" Larison, M (2016). L'Être en forme. Dialectique et phénoménologie dans la dernière philosophie de Merleau-Ponty. Milán: Mimesis.

» Lefort, C. (1978). Sur une colonne absente. París: Gallimard.

» Lefort, C. (1981). L'invention démocratique. París: Fayard. 
» Lefort, C (1986). Essias sur le politique. París: Seuil.

» Lévi-Strauss, C. (1964). El pensamiento salvaje. México: FCE.

» Merleau-Ponty, M. (1945). Phénoménologie de la perception. París: Gallimard.

» Merleau-Ponty, M. (1955). Les aventures de la dialectique. París: Gallimard.

» Merleau-Ponty, M. (1960). Signes. París: Gallimard.

» Merleau-Ponty, M. (1966). Sens et non-sens. París: Nagel.

» Merleau-Ponty, M. (2003). L'institution dans L'histoire personelle. Le problème de la passivité le sommeil, l'inconscient, la mémoire. Notes de cours au Collège de France. París: Belin.

»Pocock, J. (2008). El momento maquiavélico. El pensamiento político florentino y la tradición republicana atlántica. Madrid: Tecnos.

» Reed. J. (1980). Diez días que conmovieron al mundo. Barcelona: Grijalbo.

» Revault d'Allons, M. (2006). Le pouvoir des commencements: Essai sur l'autorite. París: Seuil.

» Sartre, JP. (1943). L'Être et le Néant. París: Gallimard.

» Sartre, JP. (1949). Matérialisme et révolution. Situations III. París: Gallimard.

»Sartre, JP. (1960). La critique de la raison dialectique. París: Gallimard.

»Schmitt, C. (2009). Teología política. Madrid: Trotta.

» Tassin, E. (2012). Le maléfice de la vie à plusieurs. París: Bayard.

» Waelhens, A. (1951). Une philosophie de l'ambigüité: L'existencialisme de MerleauPonty. Louvain: Publications universitaires de Louvain. 